\title{
Adequate Number of Swallows for Pharyngeal Pressure Measurement of a Subject using High-resolution Manometry
}

\author{
Matsusato Tsuyumu ${ }^{1}$ Takanori Hama ${ }^{1}$ Takakuni Kato ${ }^{1}$ Hiromi Kojima1잉 \\ ${ }^{1}$ Department of Otorhinolaryngology, Jikei University School of \\ Medicine, Tokyo, Japan \\ Int Arch Otorhinolaryngol 2021;25(1):e81-e87. \\ Address for correspondence Matsusato Tsuyumu, MD, Department \\ of Otorhinolaryngology, Jikei University School of Medicine, 3-25-8 \\ Nishi-shimbashi, Minato-ku, Tokyo 105-8461, Japan \\ (e-mail: tsuyumu@jikei.ac.jp).
}

\begin{abstract}
Keywords

- manometry methods

- pharynx physiology

- upper esophageal sphincter

Introduction The number of pressure measurements that need to be recorded using high-resolution manometry (HRM) for the accurate evaluation of pharyngeal function is not well established.

Objective The purpose of this study is to clarify the number of swallows required to obtain an accurate pharyngeal manometric profile of a person.

Methods Forty healthy adults performed a dry swallow and bolus swallows using 3-, $5-$, or $10 \mathrm{ml}$ of water and underwent measurements using the Starlet HRM system. Each subject underwent 10 swallows for each of the four bolus volume conditions.

Results The mean of up to seven measurements of maximum pre-swallow upper esophageal sphincter pressure with $10 \mathrm{ml}$ of swallow was close to the mean of up to eight measurements in $95 \%$ of the subjects. Similarly, the rate of change of the average for the eighth and ninth measurements and the rate of change for the average of the ninth and tenth measurements were less than $5 \%$. When the other parameters were similarly measured up to the sixth measurement, no major change in the average value was observed even if more measurements were taken.

Conclusion A minimum of six measurements are required, and seven swallows are sufficient for evaluating the pharyngeal manometric profile of a single person. This number of measurements can be a useful criterion when performing HRM measurements on individual subjects.
\end{abstract}

\section{Introduction}

High-resolution manometry (HRM) has been widely used for the evaluation of esophageal function. In recent years, HRM has also been used for the analysis of pharyngeal function. ${ }^{1}$ As HRM can quantitatively measure pharyngeal pressure and objectively evaluate swallowing function, it can be useful for evaluating pharyngeal function in patients with dysphagia. ${ }^{2-4}$ However, questions related to the number of times pressure measure- ments need to be repeated have arisen ever since traditional manometry has been used for this purpose. It has been accepted that there is considerable intrasubject variability among the measurements, and swallowing needs to be repeated at least 10 times during conventional assessment. ${ }^{5}$ In the Chicago classification, 10 measurements of esophageal pressure using HRM were recommended. ${ }^{6}$ The Chicago classification may have taken the intrasubject variability into account, but the basis for the number of measurements was not stated. Regarding the received

October 24, 2019

accepted

DOI https://doi.org/

10.1055/s-0040-1702966. ISSN 1809-9777. 
intrasubject variability of swallowing movements, only a few studies have been performed., ${ }^{7,8}$

Of the many studies that have analyzed pharyngeal pressure using HRM, some have used the mean value of two, ${ }^{9}$ three, ${ }^{1,10-13}$ or five measurements. ${ }^{14-18}$ Only a few studies ${ }^{19,20}$ used the average of 10 measurements, as recommended by the Chicago classification. Since the previous studies were able to find some tendency of intrapharyngeal pressure by targeting a large number of subjects, a smaller number of measurements for a subject may be permitted. However, to measure a manometric profile for a single subject, it is unclear how many measurements are necessary, and it may not be appropriate to make a smaller number of measurements. Although ten swallows per person may provide sufficiently reliable data, it is a burdensome test for the subject. Therefore, inspection as few times as possible is desired. We hypothesize that the average value from less than 10 measurements is also a reliable indicator. The purpose of this study is to clarify the number of swallows required to obtain an accurate manometric profile.

\section{Methods}

\section{Study Design and Period}

A cross-sectional study was conducted between March 2014 and December 2018 at our department.

\section{Subjects}

Forty healthy subjects ( 20 men and 20 women) with a mean age of 32.5 years (range, 21-57 years) agreed to be voluntarily examined using HRM. All subjects were recruited from the medical staff by an in-facility notice or word of mouth. The subjects did not have dysphagia, dysphonia, reflux symptoms, neurological or muscular disease, and were not taking medications known to interfere with swallowing. All subjects underwent transnasal laryngo fiberscopy and were confirmed to show no morphological abnormalities in the pharynx/ larynx. This study protocol was approved by the Ethics Committee of the appropriate institutional review board.

\section{Equipment}

The Starlet HRM system (Star Medical Inc., Tokyo, Japan) and a catheter (Unisensor AG, Attikon, Switzerland) with 20-channel solid-state sensors spaced at $1-\mathrm{cm}$ intervals were used for the measurements. The sensors are covered by circumferential soft membranes with fluid inside. The catheter diameter is $4.0 \mathrm{~mm}$, and the diameter of each sensor is $5.8 \mathrm{~mm}$. Each sensor detected pressure over the entire circumference, and manometric data were collected on a personal computer using a sampling frequency of $40 \mathrm{~Hz}$.

\section{Measurements}

The subjects did not eat or drink anything for at least 4 hours before testing. They were seated in a neutral cervical position during the measurement process. The nasal cavities were anesthetized with a cotton swab soaked in topical 4\% lidocaine. The manometric catheter was lubricated with topical $2 \%$ viscous lidocaine to ease its passage through the pharynx, inserted via the nasal cavity, and then positioned with its 20 channels straddling the pharynx and the upper esophageal sphincter (UES). The subject underwent 10 consecutive dry swallows, and 10 consecutive $3-\mathrm{ml}, 5-\mathrm{ml}$, and $10-\mathrm{ml}$ swallows.

\section{Parameter Evaluation}

A dedicated HR-Stealth analytical software (Star Medical, Inc.) was used to visualize the obtained data as pressure topography plots and pressure waveforms. The different pressure values were represented by different colors. The pressure waveforms at rest and during swallowing in the velopharynx, tongue base, and UES regions were defined using previous studies. ${ }^{4,10,12,14,16-18}$ The UES pressure was measured by several contiguous sensors, and the sensor with the highest value was selected.
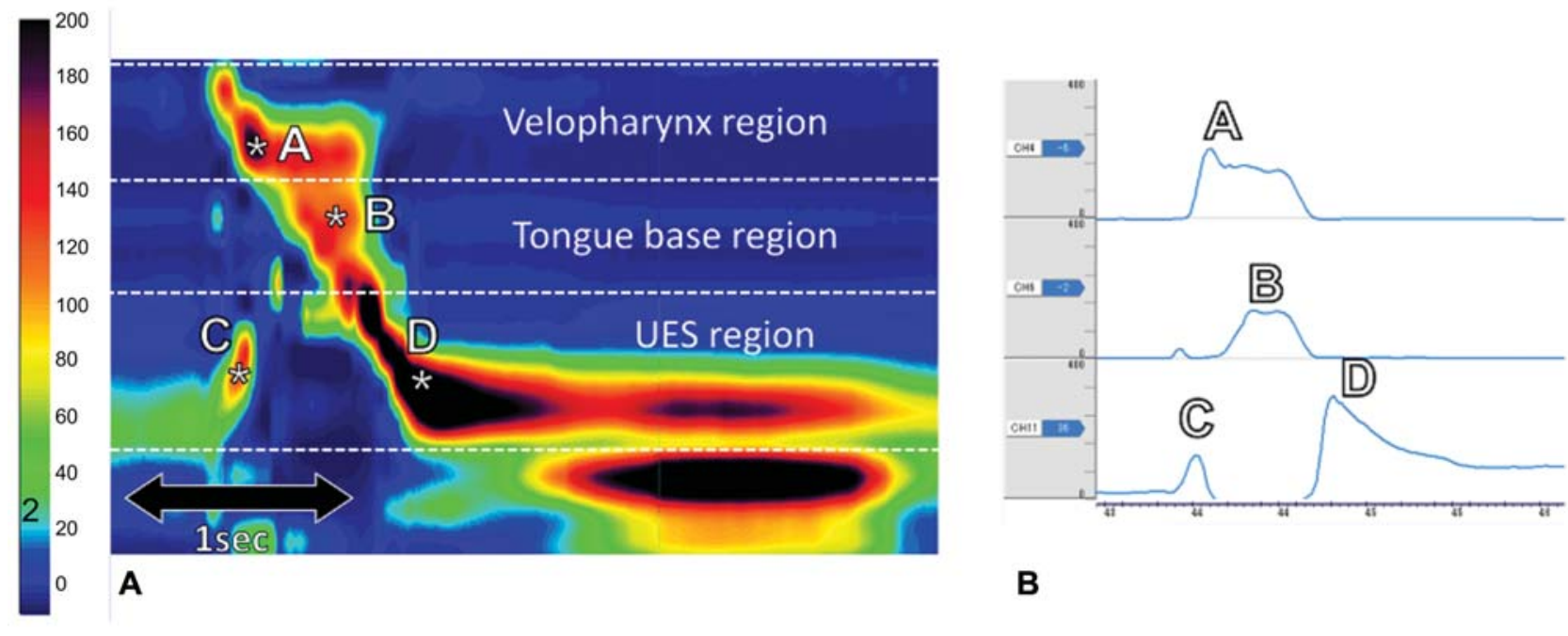

B

Fig. 1 Maximum pressure on pressure topography plots and corresponding sensor waveform. (-Figure 1A) Pressure topography plots (-Figure 1B) Corresponding sensor waveform. (A) Maximum velopharynx pressure, (B) Maximum tongue base pressure, (C) Maximum preswallow upper esophageal sphincter (UES) pressure, (D) Maximum postswallow UES pressure. The white asterisk refers to the highest pressure point in each area. 
The maximum pressure in the velopharynx and at the tongue base was measured during swallowing. In - Fig. 1, the pressure at the velopharynx region is represented by $\mathrm{A}$, and the pressure at the tongue base as B. A wide peak was observed in the tongue base region, and there were some cases in which prominent high and narrow peaks were observed. A narrow peak is created when the epiglottis strikes the manometric catheter. ${ }^{9}$ However, as it was not always observed in the present study, we considered the high and broad pressure peak in the tongue base area as the maximum tongue base pressure.

A rise in the UES pressure just before swallowing was confirmed, and maximum pre-UES pressure was defined as the preswallow UES peak pressure just before UES relaxation. In - Fig. 1, the UES region is confirmed, and the maximum preUES pressure is represented by C. After the preswallow UES peak pressure, the UES pressure value decreased markedly; almost simultaneously, pressure waveforms were generated in the velopharynx and at the tongue base. After this point, the pressure values in the velopharynx and tongue base were decreased to zero, whereas the UES pressure was increased. The increased UES pressure after swallowing was confirmed, and maximum post-UES pressure was defined as the UES peak pressure just after UES relaxation. In - Fig. 1, the maximum post-UES pressure is represented by $D$.

Velopharynx duration and tongue base duration were defined as the time between the start of increasing pressure and regression to and below the baseline level, respectively, using the sensor that recorded the maximal pressure in each region (-Fig. 2A, B). As in a previous study, ${ }^{9,14,16,17}$ the UES relaxation time was defined as the duration between the time of maximum pre-UES pressure and the time of maximum post-UES pressure (-Fig. $\mathbf{2 C}$ ).

\section{Data Analysis}

We first statistically analyzed if there was any trend in the repeated measurements for each parameter. Using the measurements obtained from the 40 subjects, the repeated mea- surement analysis of variance was used to test for differences in repeated measurements. A value of $p<0.05$ was considered statistically significant.

We defined the cumulative average value of each parameter up to the n-th as follows.

$$
\overline{\mathrm{x}}_{\mathrm{n}}=\frac{1}{n} \sum_{i=1}^{n} x_{\mathrm{n}}
$$

where $x_{n}$ is the $n$-th measured value, and $\bar{x}_{1}=x_{1}$. For each parameter in each subject, we confirmed $x_{1}$ and calculated $\bar{x}_{n}$ in the range of $2 \leq \mathrm{n} \leq 10$. It was confirmed how the cumulative average value changes as the number of measurements is increased.

The change rate of the cumulative average of the measurement values was defined as follows:

$$
\text { Rate of change }(\%): R C=\left(\left|\bar{x}_{n}-\bar{x}_{n-1}\right| / \bar{x}_{n-1}\right) \times 100 \text {, }
$$

where RC was calculated in the range of $2 \leq n \leq 10$.

It was predicted that $\overline{\mathrm{x}}_{\mathrm{n}}$ would converge to a certain value as $\mathrm{n}$ increased, that is, $\mathrm{RC}$ was predicted to converge to zero. We calculated the RC for each factor of each subject and analyzed the reduction. We considered an RC value below 5\% as sufficiently low and queried how many measurements were needed to ensure an RC value below 5\% in more than 38 of the 40 subjects ( $95 \%$ confidence interval). Repeated measurement analysis of variance was performed using the BellCurve for Excel 3.20 statistical software (Social Survey Research Information Co. Ltd., Tokyo, Japan). In addition, cumulative average and RC were calculated using Microsoft Excel (version 1909).

\section{Results}

All 40 subjects completed 40 swallows each (10 swallows for each of the 4 conditions). The transition of the measured values of the 10 swallows for each of the 4 conditions was analyzed for

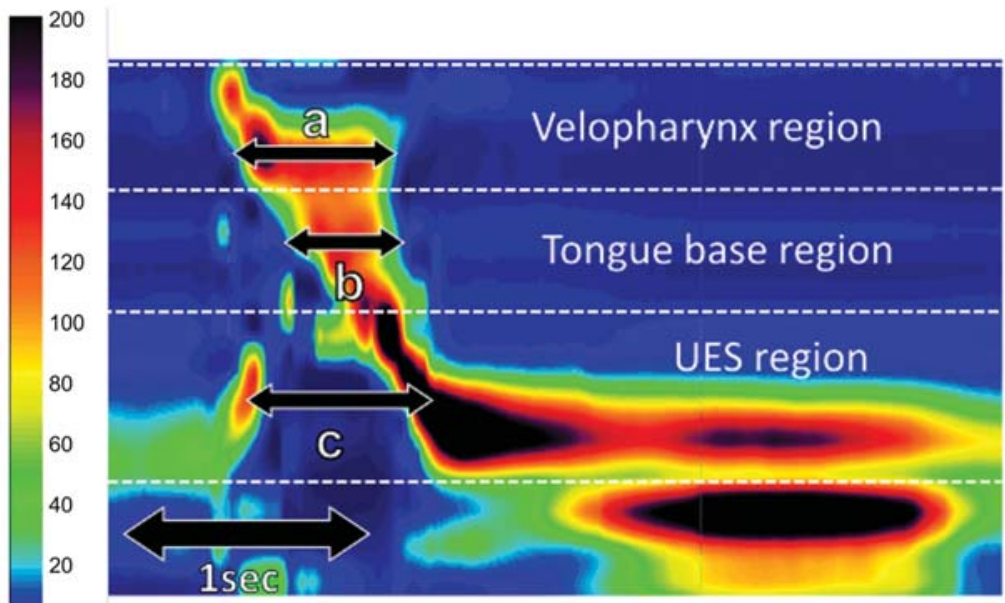

A

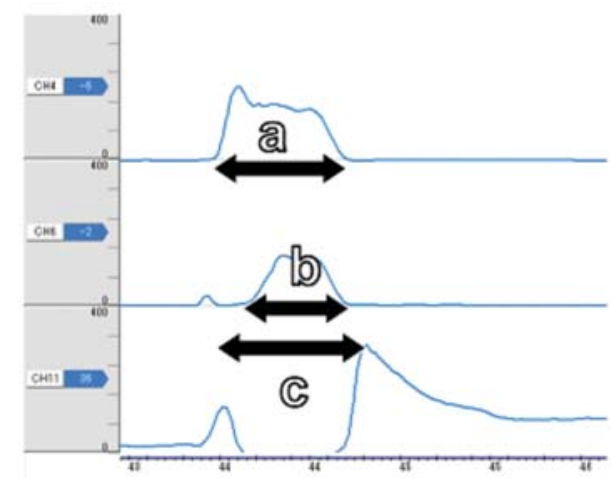

B

Fig. 2 Duration of pressure topography plots and corresponding sensor waveform. ( $\mathbf{- F i g u r e ~ 2 A ) ~ P r e s s u r e ~ t o p o g r a p h y ~ p l o t s ~ ( ~} \mathbf{- F i g u r e ~ 2 B )}$ Corresponding sensor waveform. (a) Maximum velopharynx duration, (b) Maximum tongue base duration, (c) UES relaxation time. 

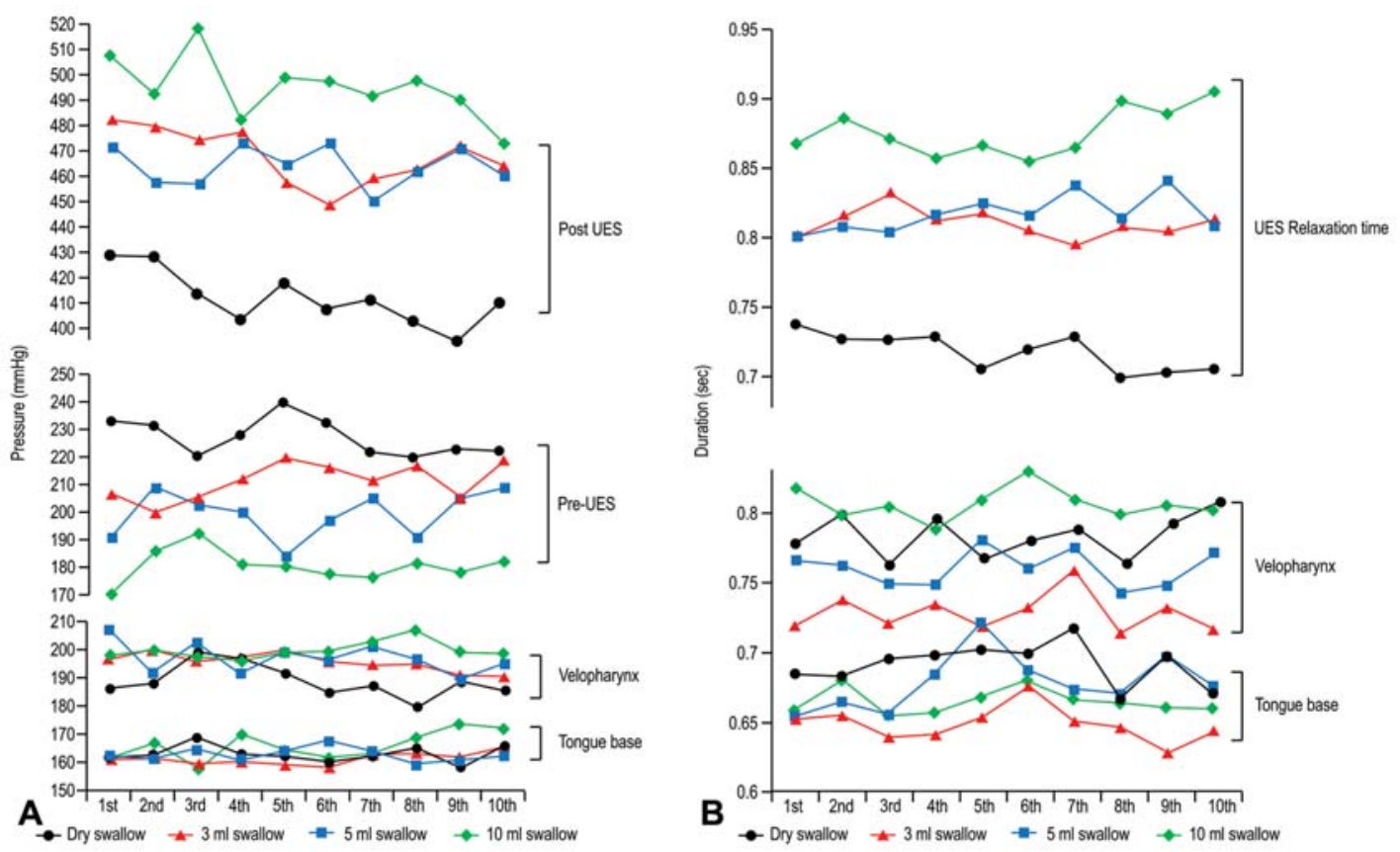

Fig. 3 The plot of mean value in the first to tenth measurements of each parameter. (A) Maximum pressure (B) Duration. The results of the analysis of variance for 10 measurements are presented in - Table 1. There were no significant differences among the 10 measurements at 4 swallow conditions for each parameter.

all 40 subjects using repeated measure analysis of variance. As a result, no significant difference was found among the $1^{\text {st }}$ to $10^{\text {th }}$ measurement values ( - Fig. $\mathbf{3 A}$, B, and $\boldsymbol{\sim}$ Table $\mathbf{1}$ ).

As $n$ increases, the predicted decreasing pattern of the RC of each parameter was observed for each subject, and the proportion of cases with $\mathrm{RC}<5 \%$ increased ( - Table 2 ). For each parameter, number of measurements required for $\mathrm{RC}<5 \%$ was different depending on 4 swallowing conditions. However, no association of the four swallowing conditions with the required number of measurements was found. The number of measurements required to achieve RC $<5 \%$ for $95 \%$ or more subjects was as follows: a) Maximum velopharynx pressure: $\mathrm{n} \geqq 5$ in 5 -ml, and $10-\mathrm{ml}$ swallow, $\mathrm{n} \geqq 6$ in dry swallow, and $\mathrm{n} \geqq 7$ in 3-ml swallow $\mathrm{b}$ ) Maximum tongue base pressure: $\mathrm{n} \geq 5$ in 3-ml swallow, $\mathrm{n} \geq 6$ in dry and $10-\mathrm{ml}$ swallow, $\mathrm{n} \geq 7$ in 5-ml swallow c) Maximum pre-UES pressure: $\mathrm{n} \geq 8$ in 10-ml swallow, $\mathrm{n} \geq 7$ in dry, 3-ml, and 5-ml swallows d) Maximum post-UES pressure: $\mathrm{n} \geq 5$ in dry swallow, $\mathrm{n} \geq 6$ in 5 -ml and 10-ml swallow, and $\mathrm{n} \geq 7$ in 3-ml swallow e) Velopharynx duration: $\mathrm{n} \geq 4$ in 5-ml swallow, $\mathrm{n} \geq 7$ in dry, $3-\mathrm{ml}$, and $10-\mathrm{ml}$ swallow f) Tongue base duration: $\mathrm{n} \geq 4$ in 10 -ml swallow, $\mathrm{n} \geq 5$ in 3-ml swallow, $\mathrm{n} \geq 6$ in dry swallow, and $\mathrm{n} \geq 7$ in 5 -ml swallow g) UES relaxation time: $\mathrm{n} \geq 4$ in all 4 conditions.

\section{Discussion}

The present study is first to evaluate the number of swallows required to obtain a pharyngeal manometric profile from a single subject. There were no statistically significant differences among the 10 measurement values of each parameter under every bolus volume swallow condition. The number of measurements required to achieve $\mathrm{RC}<5 \%$ in $95 \%$ of the subjects was $\mathrm{n} \geq 8$ under 10 -ml swallow at maximum pre-UES pressure. For maximum velopharynx pressure, maximum tongue base pressure, maximum post-UES pressure, velopharynx duration, and tongue base duration, the number of measurements required to achieve $\mathrm{RC}<5 \%$ was $\mathrm{n} \geq 7$ under any one condition of 4 bolus volume conditions, although in some other conditions it was observed that $n \geq 6, n \geq 5$, or $n \geq 4$. Exceptionally, for the UES relaxation time, we observed $n \geq 4$ under all bolus swallowing conditions.

Few studies have mentioned intrasubject variability in measurements by HRM and analyzed the required number of measurements. An appropriate number of measurements of esophageal pressure with manometry has been suggested in the previous studies by using their own different methods. One study with traditional manometry recommended recording the average value of eight measurements. ${ }^{5}$ Another study using HRM concluded that five measurements were sufficient. ${ }^{21}$ These results are somewhat different from the results of the present study.

Repeated analysis of variance showed no significant difference among the 10 measurements in each parameter. These results indicate that it is acceptable not to assume an increasing or decreasing trend of measurements due to repeated swallowing.

If we observe the result of maximum pre-UES pressure under $10-\mathrm{ml}$ swallow, the average value of the pre-UES pressure up to the 7 th time is close to the average value up to the 8th time, and more measurements do not lead to a large change in the mean value. Therefore, the average value of seven measurements in the measurement of pre-UES pressure is reliable. Similarly, the average value from six measurements are reliable for maximum velopharynx 
Table $1 \mathrm{~F}$-value and $p$-value in the repeated measurement analysis of variance

\begin{tabular}{|c|c|c|c|}
\hline \multicolumn{4}{|c|}{ a. Maximum pressure } \\
\hline & Bolus volume & F-value & $p$-value \\
\hline \multirow[t]{4}{*}{ Velopharynx } & Dry swallow & 1.618 & 0.109 \\
\hline & 3-ml swallow & 0.516 & 0.863 \\
\hline & 5-ml swallow & 1.784 & 0.067 \\
\hline & 10-ml swallow & 0.689 & 0.719 \\
\hline \multirow[t]{4}{*}{ Tongue base } & Dry swallow & 0.725 & 0.686 \\
\hline & 3-ml swallow & 0.525 & 0.857 \\
\hline & 5-ml swallow & 0.371 & 0.948 \\
\hline & 10-ml swallow & 1.013 & 0.429 \\
\hline \multirow[t]{4}{*}{ Pre-UES } & Dry swallow & 0.895 & 0.530 \\
\hline & 3-ml swallow & 1.013 & 0.429 \\
\hline & 5-ml swallow & 1.123 & 0.346 \\
\hline & 10-ml swallow & 0.604 & 0.794 \\
\hline \multirow[t]{4}{*}{ Post-UES } & Dry swallow & 1.517 & 0.140 \\
\hline & 3-ml swallow & 1.038 & 0.409 \\
\hline & 5-ml swallow & 0.761 & 0.653 \\
\hline & 10-ml swallow & 1.355 & 0.207 \\
\hline \multicolumn{4}{|l|}{ b. Duration } \\
\hline & Bolus volume & F-value & $p$-value \\
\hline \multirow[t]{4}{*}{ Velopharynx } & Dry swallow & 0.736 & 0.676 \\
\hline & 3-ml swallow & 0.558 & 0.832 \\
\hline & 5-ml swallow & 0.995 & 0.444 \\
\hline & 10-ml swallow & 0.585 & 0.809 \\
\hline \multirow[t]{4}{*}{ Tongue base } & Dry swallow & 1.220 & 0.281 \\
\hline & 3-ml swallow & 1.211 & 0.287 \\
\hline & 5-ml swallow & 1.605 & 0.112 \\
\hline & 10-ml swallow & 0.447 & 0.909 \\
\hline \multirow{4}{*}{$\begin{array}{l}\text { UES relaxation } \\
\text { time }\end{array}$} & Dry swallow & 1.677 & 0.093 \\
\hline & 3-ml swallow & 0.747 & 0.666 \\
\hline & 5-ml swallow & 1.084 & 0.374 \\
\hline & 10-ml swallow & 1.574 & 0.122 \\
\hline
\end{tabular}

Abbreviation: UES, upper esophageal sphincter.

pressure, maximum tongue base pressure, maximum postUES pressure, velopharynx duration, and tongue base duration.

Similarly, the average of three values for UES relaxation time is reliable for all bolus volume conditions. However, this number of measurements seems to be less than that for other parameters in this study. This result shows that UES relaxation time has less intrasubject variability than other parameters. Past literature reviews ${ }^{22}$ show that in many previous studies, the range of intersubject variability in UES relaxation time is narrow compared with other swallowing time parameters (e.g., pharyngeal transit time, hyoid movement duration, etc.). These results are somewhat similar to the results of the current study, which has shown that the UES relaxation time may have relatively little variability not only between subjects but within subjects as well.

The present study has certain limitations. The most significant limitation is that this study evaluated only young, healthy subjects. Essentially, HRM is expected to be used not only for the elucidation of the pathophysiology of swallowing but also for the evaluation of swallowing dysfunction. It is unclear whether elderly patients with dysphagia will produce the same results as the subjects in this study. Therefore, a similar study of elderly patients with dysphagia may be required.

Second, the UES minimum pressure is also often analyzed as a parameter of HRM. However, RC, the index used in this study, can only be used for the proportional index. The UES 
e86 Adequate Number of Swallows for Pharyngeal Pressure Measurement Tsuyumu et al.

Table 2 Percentage of cases in which the rate of change was lower than 5\%

\begin{tabular}{|c|c|c|c|c|c|c|c|c|c|}
\hline \multicolumn{10}{|c|}{ Maximum velopharyngeal pressure } \\
\hline$N$ & 2 & 3 & 4 & 5 & 6 & 7 & 8 & 9 & 10 \\
\hline Dry swallow & 32.5 & 70 & 80 & 85 & 95 & 95 & 97.5 & 100 & 100 \\
\hline $3 \mathrm{ml}$ swallow & 52.5 & 65 & 80 & 97.5 & 90 & 95 & 95 & 97.5 & 100 \\
\hline $5 \mathrm{ml}$ swallow & 55 & 70 & 82.5 & 97.5 & 97.5 & 100 & 100 & 100 & 100 \\
\hline $10 \mathrm{ml}$ swallow & 55 & 90 & 92.5 & 97.5 & 97.5 & 95 & 95 & 100 & 100 \\
\hline \multicolumn{10}{|c|}{ Maximum tongue base pressure } \\
\hline $\mathrm{N}$ & 2 & 3 & 4 & 5 & 6 & 7 & 8 & 9 & 10 \\
\hline Dry swallow & 55 & 75 & 82.5 & 92.5 & 100 & 100 & 97.5 & 100 & 100 \\
\hline $3 \mathrm{ml}$ swallow & 70 & 85 & 90 & 97.5 & 97.5 & 97.5 & 100 & 97.5 & 97.5 \\
\hline $5 \mathrm{ml}$ swallow & 50 & 75 & 87.5 & 92.5 & 92.5 & 97.5 & 97.5 & 97.5 & 100 \\
\hline $10 \mathrm{ml}$ swallow & 55 & 75 & 87.5 & 92.5 & 95 & 95 & 100 & 97.5 & 100 \\
\hline \multicolumn{10}{|c|}{ Maximum pre-UES pressure } \\
\hline $\mathrm{N}$ & 2 & 3 & 4 & 5 & 6 & 7 & 8 & 9 & 10 \\
\hline Dry swallow & 40 & 52.5 & 70 & 75 & 82.5 & 95 & 97.5 & 95 & 100 \\
\hline $3 \mathrm{ml}$ swallow & 45 & 47.5 & 70 & 87.5 & 87.5 & 95 & 97.5 & 97.5 & 95 \\
\hline $5 \mathrm{ml}$ swallow & 25 & 57.5 & 67.5 & 77.5 & 85 & 95 & 97.5 & 97.5 & 97.5 \\
\hline $10 \mathrm{ml}$ swallow & 30 & 57.5 & 62.5 & 75 & 75 & 90 & 95 & 95 & 95 \\
\hline \multicolumn{10}{|c|}{ Maximum post-UES pressure } \\
\hline $\mathrm{N}$ & 2 & 3 & 4 & 5 & 6 & 7 & 8 & 9 & 10 \\
\hline Dry swallow & 47.5 & 67.5 & 75 & 95 & 95 & 95 & 97.5 & 100 & 100 \\
\hline $3 \mathrm{ml}$ swallow & 40 & 62.5 & 85 & 90 & 92.5 & 95 & 97.5 & 97.5 & 95 \\
\hline $5 \mathrm{ml}$ swallow & 47.5 & 77.5 & 87.5 & 87.5 & 97.5 & 95 & 100 & 100 & 100 \\
\hline $10 \mathrm{ml}$ swallow & 45 & 70 & 85 & 82.5 & 95 & 95 & 95 & 100 & 97.5 \\
\hline \multicolumn{10}{|c|}{ Velopharyngeal duration } \\
\hline $\mathrm{N}$ & 2 & 3 & 4 & 5 & 6 & 7 & 8 & 9 & 10 \\
\hline Dry swallow & 52.5 & 75 & 75 & 92.5 & 92.5 & 95 & 97.5 & 97.5 & 100 \\
\hline $3 \mathrm{ml}$ swallow & 67.5 & 72.5 & 80 & 92.5 & 92.5 & 95 & 100 & 100 & 97.5 \\
\hline $5 \mathrm{ml}$ swallow & 72.5 & 90 & 95 & 95 & 97.5 & 100 & 100 & 97.5 & 100 \\
\hline $10 \mathrm{ml}$ swallow & 57.5 & 92.5 & 92.5 & 95 & 85 & 95 & 100 & 100 & 100 \\
\hline \multicolumn{10}{|c|}{ Tongue base duration } \\
\hline$N$ & 2 & 3 & 4 & 5 & 6 & 7 & 8 & 9 & 10 \\
\hline Dry swallow & 35 & 72.5 & 85 & 92.5 & 95 & 100 & 97.5 & 100 & 100 \\
\hline $3 \mathrm{ml}$ swallow & 47.5 & 70 & 92.5 & 95 & 95 & 100 & 97.5 & 100 & 100 \\
\hline $5 \mathrm{ml}$ swallow & 45 & 77.5 & 82.5 & 90 & 92.5 & 100 & 100 & 100 & 100 \\
\hline $10 \mathrm{ml}$ swallow & 52.5 & 82.5 & 95 & 95 & 95 & 100 & 100 & 100 & 100 \\
\hline \multicolumn{10}{|c|}{ UES relaxation time } \\
\hline $\mathrm{N}$ & 2 & 3 & 4 & 5 & 6 & 7 & 8 & 9 & 10 \\
\hline Dry swallow & 70 & 75 & 95 & 97.5 & 100 & 100 & 100 & 100 & 100 \\
\hline $3 \mathrm{ml}$ swallow & 55 & 75 & 95 & 100 & 97.5 & 100 & 100 & 100 & 100 \\
\hline $5 \mathrm{ml}$ swallow & 70 & 82.5 & 95 & 97.5 & 100 & 97.5 & 100 & 97.5 & 100 \\
\hline $10 \mathrm{ml}$ swallow & 62.5 & 87.5 & 97.5 & 97.5 & 100 & 100 & 100 & 100 & 100 \\
\hline
\end{tabular}

Abbreviations: N, number of measurements; UES, upper esophageal sphincter. 
minimum pressure is an interval index; therefore, it is not appropriate for RC to be used for it. A different statistical approach may be required to analyze the number of measurements required for the UES minimum pressure.

\section{Conclusion}

Our study showed that a minimum of six measurements are required, and over seven swallows are sufficient for the evaluation of the pharyngeal manometric profile of a single person. We could not confirm the trend of the required number of swallows by bolus volume. The results of this study may answer the unresolved question of how many measurements are needed to obtain a reliable manometric profile from a single subject. High-resolution manometry may be expected to be applied to elderly people and patients with dysphagia, and similar studies are needed for such people with the corresponding characteristics.

\section{Ethical Approval}

This study protocol was approved by the Ethics Committee of the Jikei University School of Medicine [approval number: 25-199 (7334)].

\section{Conflict of Interests}

The authors have no conflict of interests to declare.

\section{Acknowledgments}

This article is the result of work supported by Ms. Norie Imagawa and Ms. Yuiko Kondo.

\section{References}

1 Takasaki K, Umeki H, Enatsu K, et al. Investigation of pharyngeal swallowing function using high-resolution manometry. Laryngoscope 2008;118(10):1729-1732

2 Omari T, Schar M. High-resolution manometry: what about the pharynx? Curr Opin Otolaryngol Head Neck Surg 2018;26(06): 382-391

3 Suh JH, Park D, Kim IS, Kim H, Shin CM, Ryu JS. Feasibility of highresolution manometry for decision of feeding methods in patients with amyotrophic lateral sclerosis. Medicine (Baltimore) 2019;98 (23):e15781

4 Hoffman MR, Jones CA, Geng Z, et al. Classification of highresolution manometry data according to videofluoroscopic parameters using pattern recognition. Otolaryngol Head Neck Surg 2013;149(01):126-133

5 De Vault K, Castell J, Castell D. How many swallows are required to establish reliable esophageal peristaltic parameters in normal subjects? An on-line computer analysis. Am J Gastroenterol 1987; 82(08):754-757

6 Kahrilas PJ, Bredenoord AJ, Fox M, et al; International High Resolution Manometry Working Group. The Chicago Classifica- tion of esophageal motility disorders, v3.0. Neurogastroenterol Motil 2015;27(02):160-174

7 Peladeau-Pigeon M, Steele CM. Age-related variability in tongue pressure patterns for maximum isometric and saliva swallowing tasks. J Speech Lang Hear Res 2017;60(11):3177-3184

8 Jones CA, Meisner EL, Broadfoot CK, Rosen SP, Samuelsen CR, McCulloch TM. Methods for measuring swallowing pressure variability using high-resolution manometry. Front Appl Math Stat 2018;4:23

9 Ryu JS, Park D, Oh Y, Lee ST, Kang JY. The effects of bolus volume and texture on pharyngeal pressure events using high-resolution manometry and its comparison with videofluoroscopic swallowing study. J Neurogastroenterol Motil 2016;22(02):231-239

10 Matsubara K, Kumai Y, Samejima Y, Yumoto E. Swallowing pressure and pressure profiles in young healthy adults. Laryngoscope 2014;124(03):711-717

11 Nativ-Zeltzer N, Logemann JA, Zecker SG, Kahrilas PJ. Pressure topography metrics for high-resolution pharyngeal-esophageal manofluorography-a normative study of younger and older adults. Neurogastroenterol Motil 2016;28(05):721-731

12 Takasaki K, Umeki H, Enatsu K, Kumagami H, Takahashi $\mathrm{H}$. Evaluation of swallowing pressure in a patient with amyotrophic lateral sclerosis before and after cricopharyngeal myotomy using high-resolution manometry system. Auris Nasus Larynx 2010;37 (05):644-647

13 Lan Y, Xu G, Dou Z, Wan G, Yu F, Lin T. Biomechanical changes in the pharynx and upper esophageal sphincter after modified balloon dilatation in brainstem stroke patients with dysphagia. Neurogastroenterol Motil 2013;25(12):e821-e829

14 Mielens JD, Hoffman MR, Ciucci MR, McCulloch TM, Jiang JJ. Application of classification models to pharyngeal high-resolution manometry. J Speech Lang Hear Res 2012;55(03):892-902

15 Gumbley F, Huckabee ML, Doeltgen SH, Witte U, Moran C. Effects of bolus volume on pharyngeal contact pressure during normal swallowing. Dysphagia 2008;23(03):280-285

16 McCulloch TM, Hoffman MR, Ciucci MR. High-resolution manometry of pharyngeal swallow pressure events associated with head turn and chin tuck. Ann Otol Rhinol Laryngol 2010;119(06):369-376

17 Hoffman MR, Mielens JD, Ciucci MR, Jones CA, Jiang JJ, McCulloch TM. High-resolution manometry of pharyngeal swallow pressure events associated with effortful swallow and the Mendelsohn maneuver. Dysphagia 2012;27(03):418-426

18 Mielens JD, Hoffman MR, Ciucci MR, Jiang JJ, McCulloch TM. Automated analysis of pharyngeal pressure data obtained with high-resolution manometry. Dysphagia 2011;26(01):3-12

19 Lee TH, Lee JS, Hong SJ, et al. Impedance analysis using high-resolution impedance manometry facilitates assessment of pharyngeal residue in patients with oropharyngeal dysphagia.J Neurogastroenterol Motil 2014;20(03):362-370

20 Silva LC, Herbella FAM, Neves LR, Vicentine FP, Neto SP, Patti MG. Anatomophysiology of the pharyngo-upper esophageal area in light of high-resolution manometry. J Gastrointest Surg 2013;17 (12):2033-2038

21 Dantas RO. Effect of successive swallows on oesophageal motility of normal volunteers, patients with Chagas' disease and patients with idiopathic achalasia. Neurogastroenterol Motil 2003;15(01): 57-62

22 Molfenter SM, Steele CM. Temporal variability in the deglutition literature. Dysphagia 2012;27(02):162-177 